\section{2. - 5.11.2006 \\ DAGG-Kongress}

,Spielräume der Zukunft - Gruppen als kreatives Potenzial in Sozialisation und Bildung ‘

Bonn, Universitätsklub

Kontakt:

www.dagg.de

\section{2. - 5.5.2007}

6. Congreso Iberoamericano de Psicodrama

6. Iberoamerican Congress of Psychodrama ,Psychodrama in Cultural Syndromes and Conflicts'

La Coruña, Spanien

Kontakt: http://fidp.net

\title{
Verzeichnis der Themenhefte
}

$\begin{array}{ll}\text { 1/2002 } & \text { Wirkfaktor Gruppe* } \\ 2 / 2002 & \text { Trauma, Störung und Ressource* } \\ 1 / 2003 & \text { Rollenwechsel - Rollentausch* } \\ 2 / 2003 & \text { Kreativität wagen* } \\ 1 / 2004 & \text { Psychodramatisches Handeln in der } \\ & \text { Sozialen Arbeit } \\ 2 / 2004 & \text { Sucht } \\ 1 / 2005 & \text { Teamentwicklung /Teamberatung } \\ 2 / 2005 & \text { Szenenaufbau und Aufstellungen } \\ 1 / 2006 & \text { Junge PsychodramatikerInnen }\end{array}$

*) Ausgabe leider vergriffen

\section{in Vorbereitung:}

2/2006 Psychodrama und Gesellschaft

1/2007 Aggression

2/2007 Supervision, Beratung, Coaching

1/2008 Körper

2/2008 Rollenspiel

\author{
(Hrsg. U. Fangauf) \\ (Hrsg. R. Krüger, K. Weber) \\ (Hrsg. M. Schacht, H. Pruckner) \\ (Hrsg. U. Fangauf) \\ (Hrsg. F. Stimmer) \\ (Hrsg. U. Fangauf, M. Zwilling) \\ (Hrsg. M. Gellert) \\ (Hrsg. R. Krüger, K. Weber) \\ (Hrsg. U. Fangauf, C. Stadler)
}

(Hrsg. H. Pruckner, M. Schacht)

(Hrsg. M. Schacht, K. Weber)

(Hrsg. F. Stimmer, M. Gellert)

(Hrsg. U. Fangauf, C. Pajek)

(Hrsg. R. Krüger, C. Stadler) 